\title{
The Enlightenment of Installation Art to Sculpture Creation
}

\author{
Yujiu Liu \\ Ningxia Teachers University, Guyuan, Ningxia, 756000
}

Keywords: installation art; sculpture; influence

\begin{abstract}
With the development of society, people's pursuit of material life has gradually increased, and people's pursuit of culture and art has become more and more intense. In the 1960's, installation art had a strong impact on the characteristics of sculpture art, and on sculpture. Creation brings some enlightenment. The installation art is a form of comprehensive art. Starting from the elements of the work, emotions will be expressed in a certain space environment. There are various ways of expression, and the form of writing works smoothly. The creator mainly integrates emotions into creative thoughts, and the style is reflected in works. The installation art displays the art form in its unique form, giving viewers different feelings. Appreciating the works from different angles will bring different feelings. There is a certain difference between installation art and sculpture, and the process of creation is mainly emphasized, which can make the device art concept accepted by many audiences and has certain aesthetic characteristics.
\end{abstract}

\section{Introduction}

The installation art is highly innovative and has its decorativeness within a certain spatial scope. With the development of society, various art forms have a certain way of showing. There is a certain degree of interoperability between art and art, and various arts. The constant interrelation between each other forms an artistic style. In this case, installation art will decorate the sculpture to make the sculpture more creative. The installation art integrates venues and materials into an integrated art. In practice, it gradually presents different artistic sensations. Contemporary art impacts traditional art and has an important influence on sculpture, especially in sculpture. Art is widely used.

The sculptures are mainly made of materials using their tools. They display works with different meanings through materials with adhesive effects, and are presented through volume and space in the process. It is a representation of the shape of the object. These stylings are all made through production, and the materials need to be practical during the production process. This is a more traditional sculpture. Sculpture also has intrinsic meaning. In practical terms, sculpture is the processing of materials. Some materials are subtracted through processing and some materials are added. Sculpture works mainly through the thoughts and actions of people who process it. Objects. With the development of science and technology, a large number of emerging materials in the manufacturing industry and in the industry are constantly emerging, which constitutes a certain transformation of the sculptural creation materials. The sculpture technique is also constantly innovating. Sculptures are carried out in a variety of ways and the charm of the sculpture is displayed in a three-dimensional space.

\section{Certain Characteristics of Sculpture}

Sculpture is an art with an aesthetic sense. It plays an important role in the plastic arts. The so-called plastic arts have a certain formability in the visual and modeling space. Sculpture has precisely this part of the characteristics. Sculpture is a kind of shaping the entity. The process, which has a three-dimensional artistic image, can reflect real life through this image and express the emotions of the creative person. The works of different materials and sculptures are different, and they also have a different aesthetic sense of formability. Therefore, paintings can be integrated into them. However, the art of painting cannot be the same as that of sculptures.

The basis of sculpture is mainly through actual material creation. No matter what kind of 
sculpture works, from small to large, from simple to complex, indoor or outdoor, from the use of materials to the construction of the structure needs to be transformed The material surface is treated. In the production process, the material needs to be produced and the production process needs to be very thorough. Therefore, the sculpture not only needs thinking activities but also needs physical activity, and the process of its creation is mixed.

The materials used in the sculpture need to be produced by different methods. Therefore, there are many kinds of modeling methods. For example, in the engraving of wood and stone, cutting and engraving can be performed. In the engraving of metal materials, it is necessary to carry out engraving by means of casting. In clay sculpture, grouting is required, and many comprehensive sculptures require different sculptures. Materials are combined using different methods. These methods need to be linked by materials and materials. There are so many ways in sculpture that it is these methods that can produce different artistic effects for the production of sculptures. Therefore sculpture has a variety of features.

In the process of sculpture, the material of the sculpture is rich and varied, so that various sculpture works can be presented in the eyes of the appreciator. In the process of sculpture, the art form needs to be displayed, and the sculpture is to be used through the use of materials. The whole work is created. The variety of materials used for sculpture makes the art of sculpture appear in different forms. The sculpture materials include gypsum, cement, metal, glass, etc. The texture and tolerance of the same material are different in different regions. Sculptures are performed by different materials and different properties. Different sculpture works are presented. For example, in the process of making sculptures, sand and so on are used. Sand is divided into sea sand and river sand. The shape of the sculpture is different through the use of different materials. With the development of science and technology, the technique of sculpture continues to advance. Manufacturing will be more malleable and environmentally friendly.

The great significance of sculpture lies in appreciation. For the aesthetics of the sculpture process, it is incomparable to many other arts. In the process of sculpture, the sculpture works are presented through the crystallization of the sculptor's wisdom. The way of presenting is through different Sculpture materials show the texture of different works. Combining specific sculptures in a form of expression conforms to the aesthetic framework. In this way, viewers will resonate with the author. For the works of sculpture, certain space needs to be used to apply certain physical entities. Appreciators can not only appreciate this kind of sculpture, but also can feel real. Different works can be appreciated from different perspectives. From the angle of body odor, the feeling of this heart is unique to the sculpture. The three-dimensional three-dimensional is that the viewer can actually see it from every angle. It is also not available in other works of art. The art of sculpture is constantly evolving. From traditional sculptures to modern sculptures, its characteristics are obvious and it has a certain degree of plastic art. This kind of art has become the culture of sculpture creation. It is different from other art works in the natural world and is also creative. Sculpture is a kind of art that comes from life. In the process of social development, it constantly reflects real life. Through actual shaping, it embodies its aesthetics. In the expression of the author's emotions, it will hone its skills through three-dimensional. Ways to create, showing the charm of sculpture, although it is static, but more ornamental value.

\section{The Impact of Installation Art on Sculpture}

The installation art is an art aesthetic art. The installation art was developed in the 1960s. The installation art is an exotic word. It has a certain connection with the concept art and is also a product of a material culture. The apparatus is mainly a collection. The extension of the body is the different evolution of space. It is the coexistence of people and objects and the environment. The installation art is to disrupt and reconstruct the objects by segmentation, superposition, etc., and then display them. This method has been given a new art display method and creative method, and can be reorganized immediately during direct superposition. This value is directional. The actual application of the finished product itself has increased the significance of the new work in the exhibition process. The installation art is a meaning of media and has a meaning of synthesis. 
Because there are different artistic expression methods and art classification in installation art, many reversed methods appear in many physical logics. It is mainly through non-logical representations or through tensions to create more creative perspectives. This view is organized by arrangement to fully reflect the changes in the world and some advanced concepts. As stationary objects are not necessarily static, or eternal objects in space are not necessarily eternal, they are constantly changing.

As an installation art, it has certain advanced artistic features and is of great significance in sculpture. As an installation art, it breaks the use of commonly used materials and three-dimensional space in sculpture art. It is not a very fancy point of view for the processing of materials and the performance of materials. It is mainly used through the use of objects that meet the concept of expression, and is used in the process of utilization. filter. The idea of the work is combined through the work. This way of thinking breaks the traditional method of production in sculpture, has the characteristics of guidance, installation art has a very important role in subversion of sculpture. First of all, the installation art provides an overall and intuitive presentation of real objects, reveals the existence of reality in relation to life and environment, and evades the styling of sculpture. Secondly, installation art regards the material of sculpture directly as an element that needs to be represented. It is part of a work of art. It will be displayed in a manual imitation form, and the performance of the material itself will be captured through the representation of the object itself. The installation arts will change the perspective of everyday products, and new observations can be made on discarded items, enhancing the aesthetics of the art. The installation art uses the space environment as a carrier and attracts the people who appreciate it, so that the viewer and the creator both resonate in such a carrier, and realize the function of the source of art and life. The installation art has a wide range of arts and can be applied to architecture and music, movies and poetry, etc., breaking the impact of art classification on sculpture art. At the same time, the installation art is very variegated. Creators can combine different ways in the display of works and increase or decrease the number of different exhibitions according to their needs. The installation art has broken the new barriers to the modeling of the sculpture art, combined the traditional art of sculpture with the art, and used the ready-made art of finished art to fade the artistry of traditional art, breaking the habitual way of thinking, and taking the overall space as The viewers and the carrier of the environment have eliminated the division of the art space and expanded the works to break the static nature of the sculpture. Under the change of the installation art, the inherent concept of the sculpture art was broken and the art was obtained on the other hand. The innovation has expanded the ability to shape the art and presented the integrated art form to the viewer.

\section{The Relationship between Installation Art and Sculpture}

There is a certain relationship between installation art and sculpture, both of which have certain differences and similarities. In the shaping of space and the use of materials, the materials and methods used for sculpture occupy a certain position and can be used as a kind of Static art. In the use of space, installation art and sculpture have such characteristics. The installation art and sculpture are embodied through materials. The installation art mainly emphasizes the shaping function of the original material, and its application is more extensive. The use of installation art materials has a certain degree of directivity. In the process of creation by creators, their significance is diluted, thus embodying the creators' ideas. There are certain interactive factors in the installation art and sculpture. This needs to take into account some of the needs of the venue. If the exhibition is conducted indoors, whether it is indoors or outdoors, it will have an impact on the surrounding environment. The installation art has a certain dependence. For the existence of the environment, the traditional sculpture allows the viewer to understand the sculpture through aesthetic understanding of the sculpture.

Sculpture and installation art have certain differences, and there are differences in the methods and concepts of production. Sculpture works are mainly to create works by shaping and using materials. This way is considered to be a traditional way of sculpture, which represents a form of creation for craftsmen, presented through the creator's thoughts, in the process of creation. There is 
no reproducibility. In the production process, the use of materials is very large, and the production process is also complicated. This is the crystallization of the creator's thinking and feelings and capabilities. In the installation art, there are fewer manual skills used, mainly through the reorganization of finished products. The way to do this is to combine and superimpose, which is a kind of behavior and a symbol of physical works. In traditional sculptures, sandstone is used as a sculpture material. The sculpture itself is a static work. The traditional sculpture can be viewed through many angles, and then the sculpture can be touched. The works of installation art are usually placed in the exhibition process for a relatively short period of time. This timeliness is relatively strong, and it is explored from the perspective of culture. Traditional sculpture has always been in the popular aesthetic, but installation art is mainly seen through phenomena. The hidden artistic objects and their influence on viewers are mainly conveyed through vision. Therefore, the two are different.

\section{Conclusion}

With the development of society, the concept of art has undergone a fundamental change. The installation art has played a very important role in the creation of sculpture art, breaking the traditional art concept of sculpture, integrating new art forms, and expanding the art The combination of the types of the installations compares installation art with sculpture and has gained a lot of inspiration.

\section{References}

[1] Yang Shuhan. Research on installation art of contemporary sculpture creation [J]. Modern decoration (theory), 2015, 06: 186.

[2] Sun Ligang. The characteristics of the finished products reflected in the installation art [J]. Science and Technology Vision, 2014, 22:134.

[3] Xiao Xiaoyu, Wu Bao. Emotional sculpture [J]. Art Education Research, 2017, 14:8-9.

[4] Hu Wanfeng. On the creation of contemporary puppet show modeling art[J]. Drama (Journal of Central Theater Academy), 2017, 03:32-38+73-76.

[5] Zhang Sheng. The "non-linear" characteristics of digital sculpture creation [J]. Sculpture, 2017, 05:66-67.

[6] Chu Xiaoqing. The influence of technological progress on artistic creation concept and aesthetic value orientation [J]. Art Baijia, 2016,3201:130-156+163.

[7] Li Lisi. Research on the aesthetic functions of dynamic language in contemporary artistic creation [J]. Fine Arts, 2016, 08: 76-77.

[8] Chen Chiyu. Theoretical Innovation: The Fundamental Task of the Discipline of Art Theory [J]. 100 Artists, 2011, 2704: 52-56.

[9] Zhang Xinyu, Liu Liwen. The application of interactive media art in public space art [J]. Journal of Zhejiang University of Technology (Social Sciences Edition), 2010, 903:296-300.

[10] Yuan Huaxiang, Li Mingchao. The influence of urban culture on urban sculpture creation [J]. Journal of Huazhong University of Science and Technology (City Science Edition), 2007, 01:71-76.

[11] Tian Hua, Li Xia. Issues and correspondence: Contemporary printmaking teaching seminars Summary of the Annual Meeting of the National Print Art Teaching and Creative Associations in 2006 [J]. Journal of Tianjin Academy of Fine Arts, 2007, 01:44-53. 